\title{
The Effectiveness of the Quality of Performance Using the Cost Accounting Information System in the Control of Quality Costs Study in the General Company for Electrical Industries
}

\author{
Hanan Abdullah Hassan Al-Amar \\ Qasim Ali Omran Al-Bayati ${ }^{b}$ \\ Huda Jabbar Kadhum Al-Haiyalic \\ ${ }^{a}$ University of Baghdad,Development and Continuing Education Center \\ ${ }^{b, c}$ University of Al-Furat Al-Awsat, Technical Musayyib \\ al_ammaria@yahoo.com kasimali78@yahoo.com Huda.yabbar58@yahoo.com
}

Submission date:- 27/6/2018 Acceptance date:- 31/7/2018 Publication date:- 10/2/2019

Keywords: financial, performance . quality. economic

\begin{abstract}
The financial operations which carried out by economic unity are proven treatment and documenting and continuous down to makers decision by relevance objective and timely and then to reflect on the decision maker in any center of responsibility. That's provided by the system accounting information where the source is the basis for producing important accounting information, And the cost accounting information systems of the most important information systems that deal with data processing and conversion to information of relative importance to the beneficiaries. Which is consist with The objective of the research that emphasize the importance of accounting systems in general and systems cost in particular to achieve the highest $\mathrm{c}$ The research has led to a number of results, the most important of which is the difficulty in controlling quality costs as well as the waste of economic resources in the company. The researchers recommended adherence to the technical standards to achieve the quality of performance as well as conducting a thorough examination of samples and focusing on the quality of raw materials and testing before use to reduce the proportion Damage.
\end{abstract}




\title{
فاعلية جودة الاداء باستعمال نظام معلومات محاسبة الكلفة في الرقابة على كلف الجودة دراسة في الثركة العامة للصناعات الكهربائية
}

\author{
حنان عبدالله حسن العمّار * قاسم علي عمران البياتي*** هلى جبار كاظم الحيالي

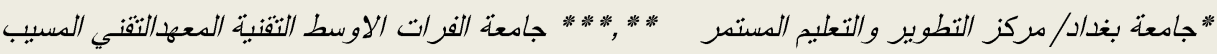

Huda.yabbar58@yahoo.com kasimali78@yahoo.com al_ammaria@yahoo.com

ان العمليات المالية التي تقوم بها الوحدات الاقتصادية يتم اثباتها ومعالجتها وتوثيقها وتدقيقها بشكل مستمر وصولا الى متخذي القرار

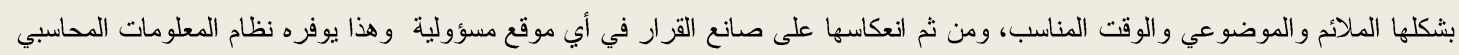

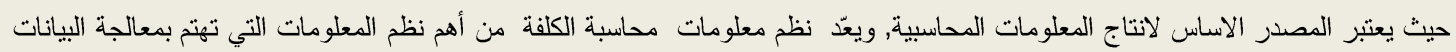

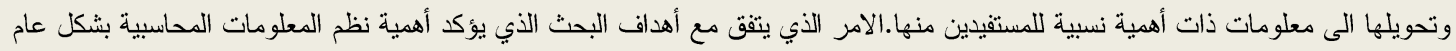

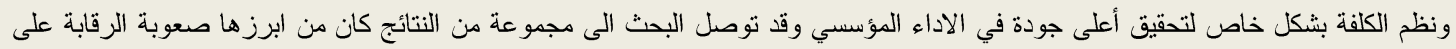

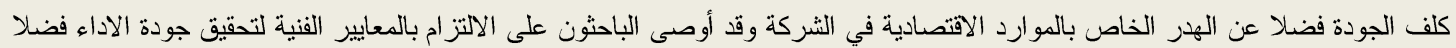

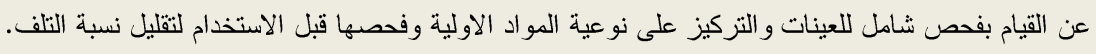
الكلمات الالأة: المالية، والأداء. نوعيه. الاقتصاديه.

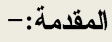

إن المؤسسات الاقتصادية لاسيما الصناعية منها تتاثر بتدفق المعلومات المناسبة في الوقت المناسب وبشكل مستمر بين المستويات الإدارية

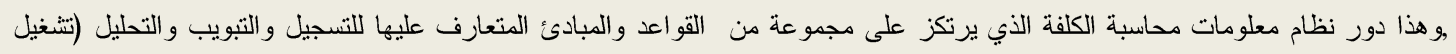

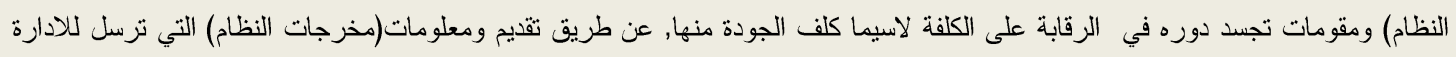
لتحقيق الاهداف الاقتصادية للمؤسسة, باستعمال بيانات الكلفة الموتوقة التي تتمنل بأحد المدخلات الاساس لهات لهذا النظام المعلوماتي, ليتم تحليلها

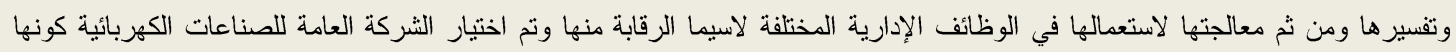

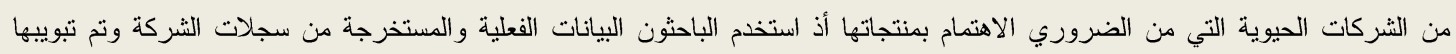

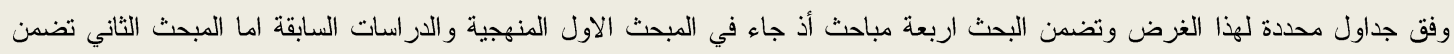
الجانب النظري وأنثتمل المبحث الثالث على تطبيق الجانب الميداني أما المبحث الرابع خصص الثئ الى نتائج البحث والهم التوصيات التي توصل اليها الباحثون.

\section{1 - منهجية البحث}

1. 1 مشكلة البحث:- عدم كفاية الرقابة على التكاليف في الشركات الصناعية ومنها الشركة العامة للصناعات الكهربائية عينة البحث لاسيما

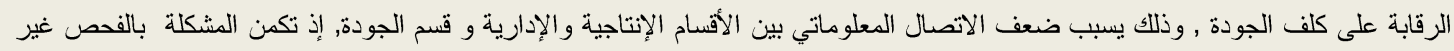

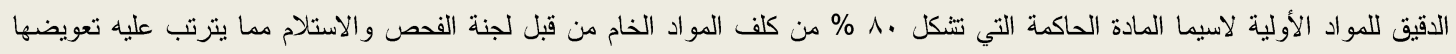
لكونها من الدرجة الثانية والثالثة ولكون عدم وجود نظام معلومات كلفة تفصيلي يصلح للتطبيق في جميع الثركات بأنو اعها , ما يترتب عليه اثلار

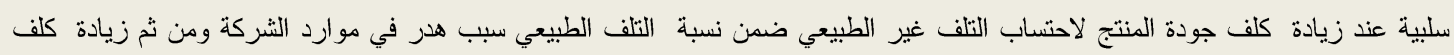
الفشل الداخلي والخارجي دون تجنها او تخفيضها عن طريق زيادة كلف المنع(الوقاية والتقييم).

r.1 أهمية البحث:- تأتي أهمية البحث من اهميةالاتصال الاداري بنظام المعلومات محاسبة الكلفة ومنها نظام الإنتاج كنظام تشغيلي بوصفه

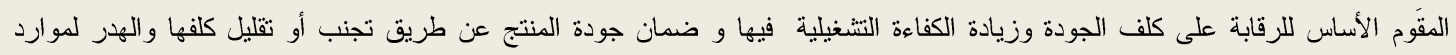
الشركة.

r.1 هدف البحث:- الوصول إلى أفضل جودة اداء مؤسسي بكلفة أقل والتأكيد على أهمية نظم المعلومات المحاسيية لاسيما النظام المحاسبي

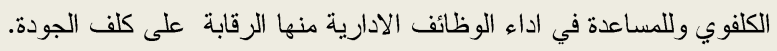


ع. 1 فرضية البحث:- يتم تجنب كلف الفشل الداخلي والخارجي وتخفيضهما عن طريق زيادة كلف المنع (الوقاية والتقييم) بتطبيق نظام معلومات كلفة بشكل كفوء وفعال للارقابة على هذه الكلف وصو لا بالمنتج إلى الجودة المطلوبة على وفق المو اصفات المعيارية. ه. 1 وسائل جمع المعلومات:- تضمنت هذه الوسائل على:

اولا:-ماهو متوفر من كتب عربية وأجنبية وشبكة الانترنت والييانات والمعلومات المالية والإحصائية للسنوات نطاق البحث المستمدة من عينة

ثانيا:-المقابلات المباشرة مع المعنيين بالموضوع بوصفها احدى الادوات البحثية المهمة التي تسهم في الحصول على بيانات ومعلومات ملائمة

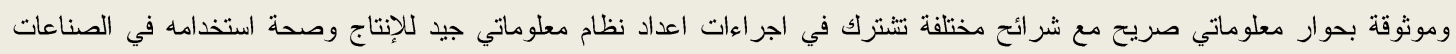
الكهربائية وتفاصيل استعمال موارد الثركة بالثكل الامثل (المواد الخام الحاكمة) وهم (مدير قسم التخطيط للانتاج, مدير قسم النوعية, مديرة

حسابات الكلفة).

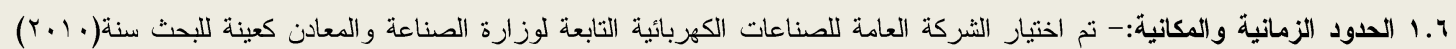
لسهولة الحصول عليها.

$$
\text { - الجانب النظري }
$$

تمهيد: تتطلب الرقابة على تكاليف الجودة الاتصال المعلوماتي الاداري ونظم معلومات محاسبة الكلفة ومنها نظام الانتاج سيتم تتاول الجانب

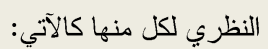

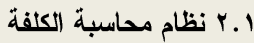

يعد نظام محاسبة الكلفة من الانظمة المهمة لنظم المعلومات المحاسبية لاستعمال معلوماته في اعداد التقارير والكشوفات المالية كافة,وله

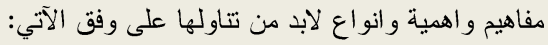
1- مفهوم نظام معلومات حسابات الكلفة

يعرف نظم المعلومات المحاسبية بأنها " مجموعة من الأنظمة الفرعية المستخدمة في تجميع وتبويب ومعالجة وتحليل وتوصيل المعلومات

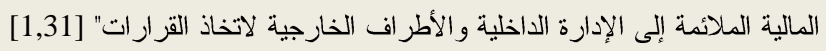
وكما عرف أيضا بمجموعة من العناصر المتداخلة والمتفاعلة مع بعضها والتي تعمل على جمع البيانات ومعالجتها وتخزينها وتوزيعها ، من الخها

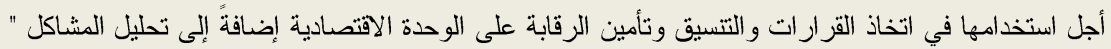

اما(النجار) فقد عرفه بأنه نظام معلوماتي دقيق ومفصل عن كيفية استعمال موارد المنظمة الإقتصادية لتحويل البيانات الاقتصادية إلى

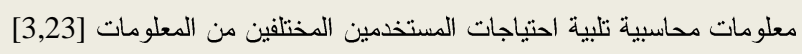
أما نظام محاسبة الكلفة فهو نظام يتم بموجبه تسجيل(التأثير ات المالية للأحداث التي تجرب في عمليات الانتاج بقاس ومر اقبة وتتبع عناصر

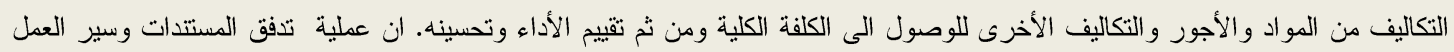

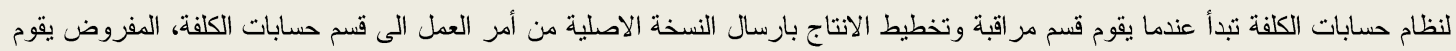

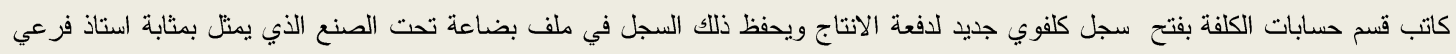

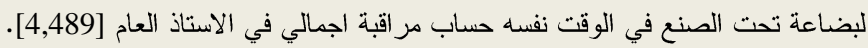

تتطلب العملية الإنتاجية لصرف مواد واجور مباشرة فضلاً عن التكاليف الصناعية غير المباشرة مستتدات ثبوتية لتتبع صرفها على الى التيل

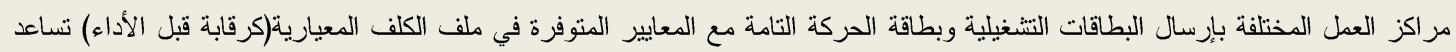

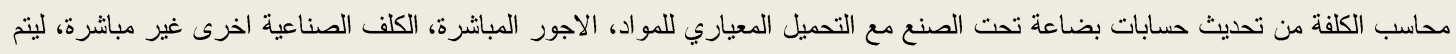

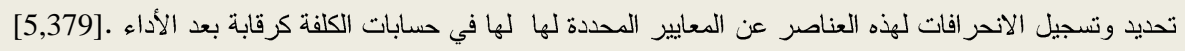
r - الاهداف الرئيسية لنظام معلومات محاسبة الكلفة: ان نظام محاسبة الكلفة يمثل الخطوة الحاسمة لنظام الإنتاج لتحقيق هدفين رئيسين هما:[6,3] ا- تزويد معلومات تخطيطية ورقابية تفصيلية للعمليات الإنتاجية والتي تستخدم بتقدير كلفة الخزين وقيمة البضاعة المباعة التي تظهر في القوائم

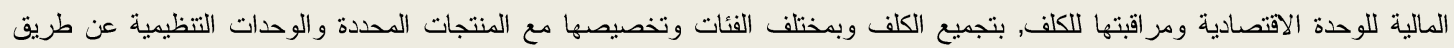

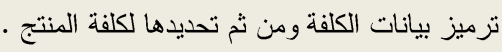




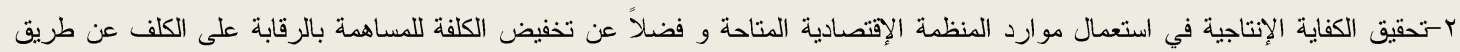

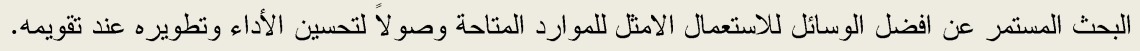

r- الأظمة الفرعية لنظم معلومات الكلفة

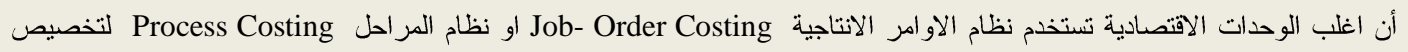
تكاليف الإنتاج, إذ أنه بموجب نظام الأو امر الانتاجية يتم تخصيص الكلف على منتجات او اعمال محددة, ويستخدم هذا النظام عندما يكون المنتج

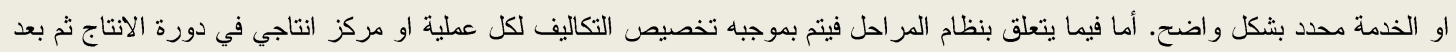

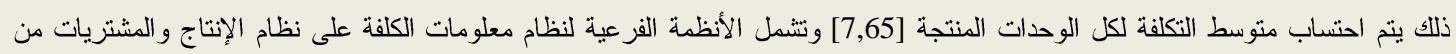

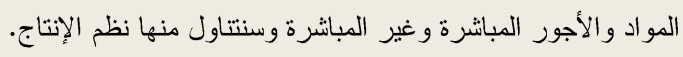

צ- نظام الإتناج

من الأنظمة الفرعية لنظام الكلفة نظام الإنتاج التشغيلي لكونه يمثل عصب النشاط في الوحدات الاقتصادية لاسيما المنتجة للسلع كأساس

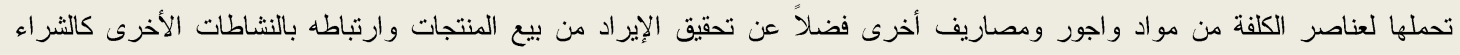

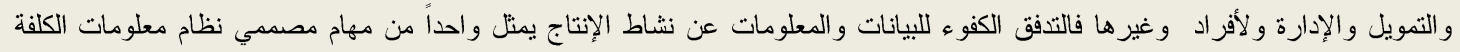

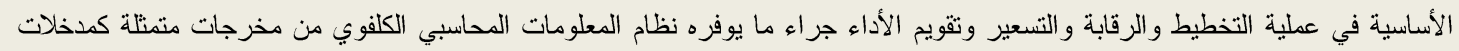

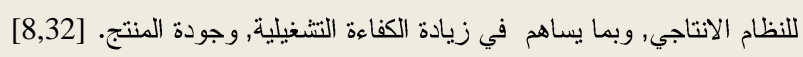

$$
\text { • - نظام معلومات الاتتاج المؤتمت (الاكتروني): }
$$

ان الثكل رقم (1) يوضح هذا النوع من نظام المعلومات المحاسبي الانتاج، نتيجة للمنتجات الجديدة يتم تحديث المواصفات لقسم الهندسة

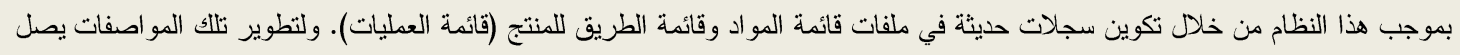

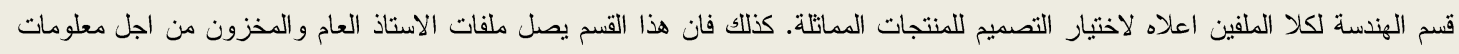

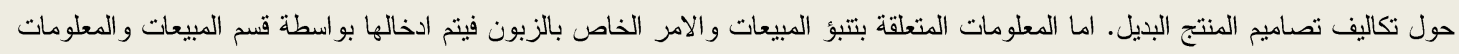

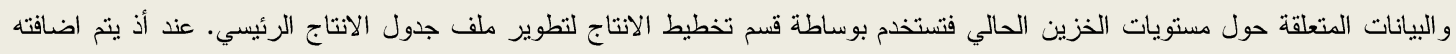

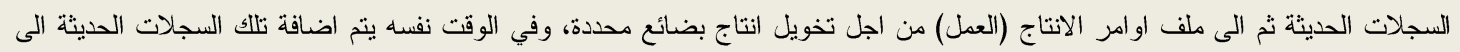

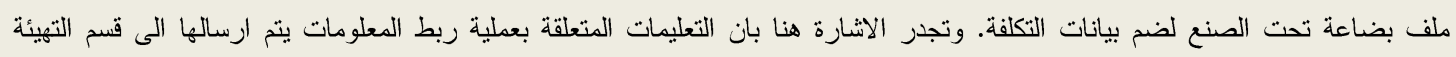

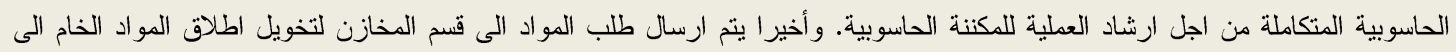
الانتاج.

ان النظام الموضح في الثكل المذكور ممكن استخدامه في نظامي الاوامر الانتاجية والمر احل. وكلا النظامين يستلزم تجميع بيانات حول

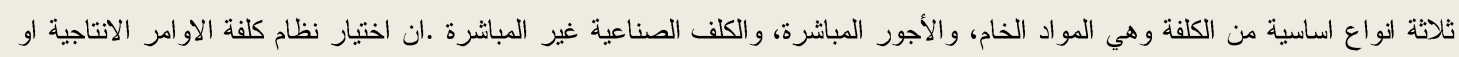

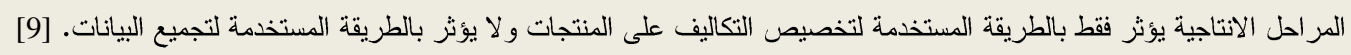


شكل رقم (1 ) لنظام المعلومات الانتاج المؤتمت

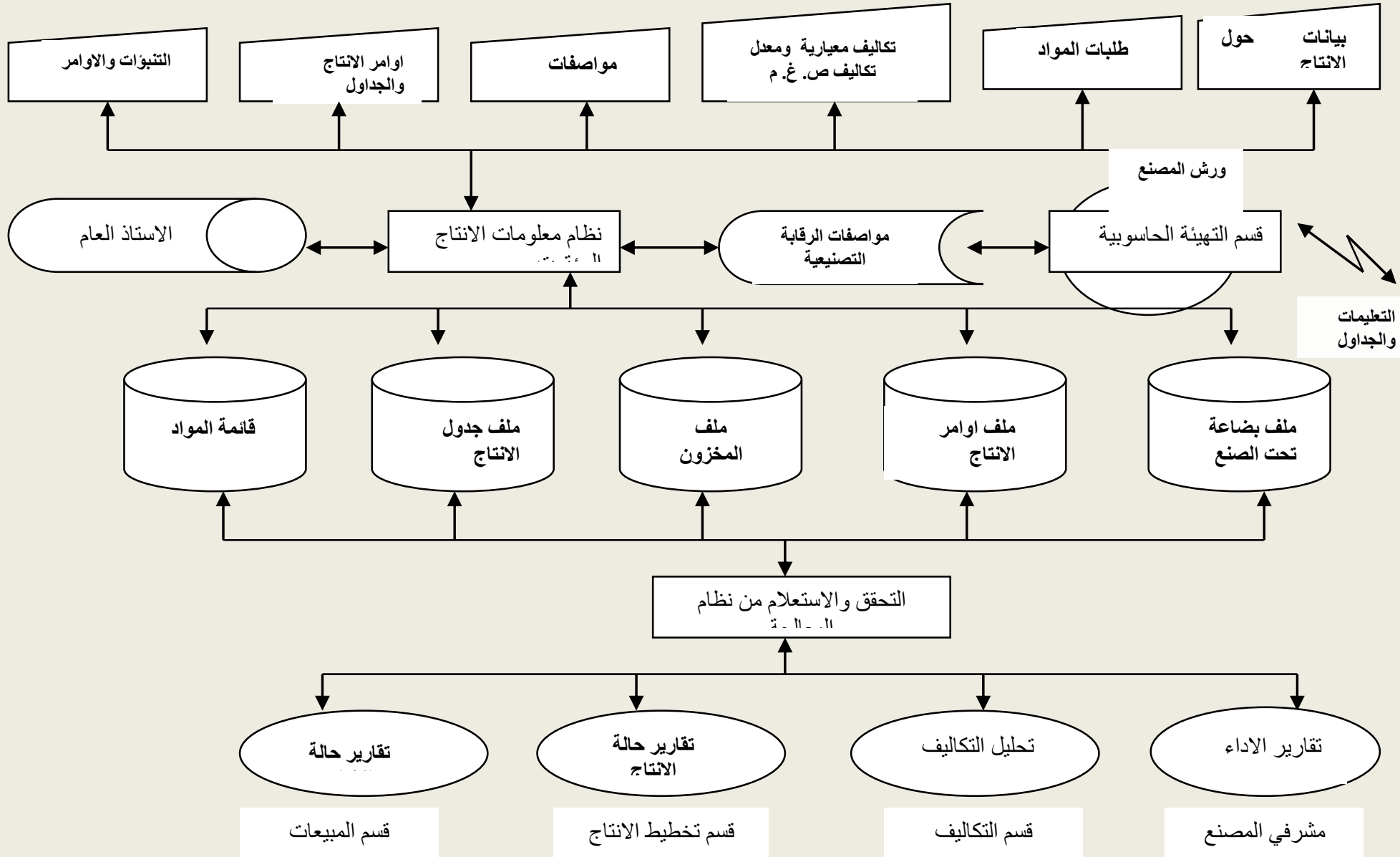

110,pp.34-36 [- تصميم نظام معلومات محاسبة الكلفة

فيما يلي المر احل الواجب اتباعها عند تصميم نظام معلومات محاسبة الكلفة:

المرحلة الاولى: مرحلة المسح الأولي الشامل لبيئة الوحدة الاقتصادية(الدراسة و المعاينة)

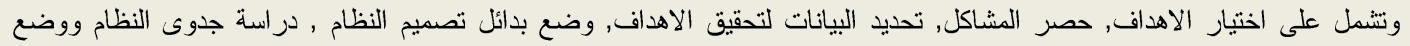

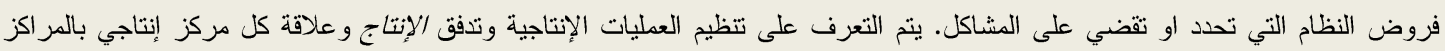

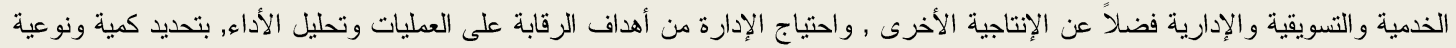

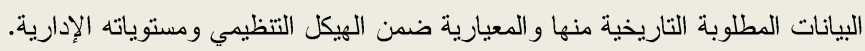
المرحلة الثانية: التصميم:-وتتمل على وضع الخطوط العريضة للنظام ومكوناته,تحديد ارتباط النظام بالأنظمة الأخرى للمعلومات, التصميم التقصيلي(تحديد الدورة المستتدية والتبويب لدليل الكلفة على وفق عناصرها والوحدة الاقتصادية والمر اكز الكلفوية فضلاً عن المجموعة الدفترية

وقو ائم وتقارير الكلفة) المرحلة الثالثة: التطبيق والتنفيذ:- وتتشل على تخطيط مراحل ونشاطات التتفيذ بجدولة زمنية وفنية, من اختيار القائمين على التتفيذ وتدريبهم, وضع بر امج تشغيل الييانات وتوثنق النظام وتعليمات تشغيله واجر اءاته الرقابية. المرحلة الرابعة التشغيل:- وتتشل على اختيار اسلوب التشغيل الملائم ,اختباره وتجربته,تحليل كلفة النظام, اعداد تقارير المتابعة والقياس المبئي ل المخرجات. المرحلة الخامسة: التقييم :- وتتمل على مقارنة مقومات النظام بانظمة مماتلة, دراسة تقارير وقوائم النظام , تحليل الكلفة/ العائد, تقييم

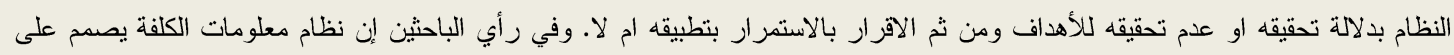


وفق المسح الاولي للمنظمة التي يتضح فيها واقع حالها من نقاط ضعف وقوة لتلافي الاولى وتعزيز الثانية للرقابة على الكلفة لاسيما كلف الجودة ومن ثم تحسين الأداء.

r. r r الرقابة على تكاليف الجودة

تمثل الرقابة على الكلفة وكلف الجودة بشكل خاص أهم وظائف نظام محاسبة الكلفة لذا سيتم تتاول مفهوم الرقابة وماييتعلق بها على وفق الآتي: ا- مفهوم الرقابة:- تتمثل الرقابة بتزويد الإدارة بثقارير الأداء بالوقت والثكل الملائم, و توفر آليات اتصال داخل المنشأة ,تتسم بالكفاءة, وتتجه

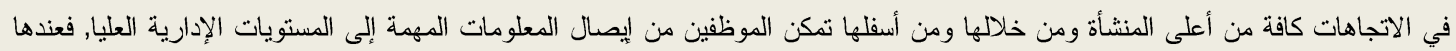

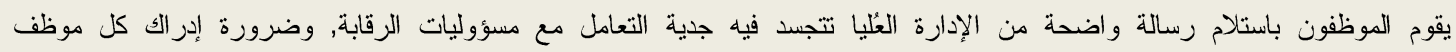

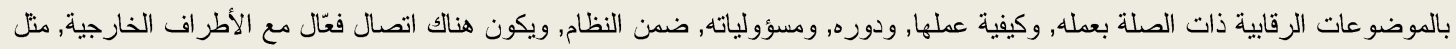

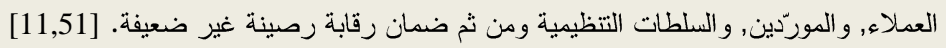
ويمكن ان تعرف بانها إجراءات وسياسات تتخذ من من قبل الإدارة, والتي تكفل تحقيق الأهداف(المنظمة) المخطط لها لتضمن التتفيذ

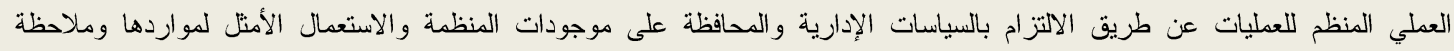

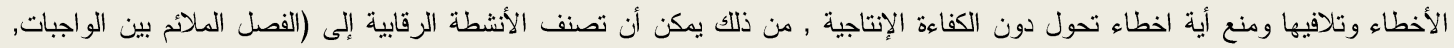

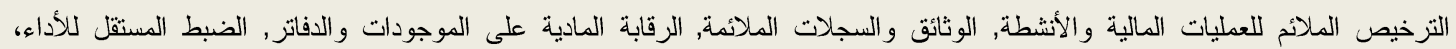

r- الرقابة على المواد الخام الحاكمة وغير الحاكمة

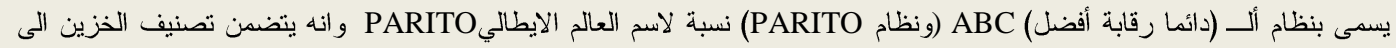

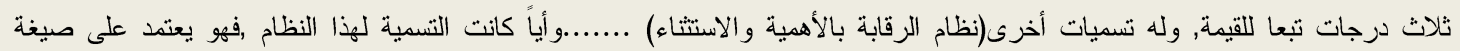

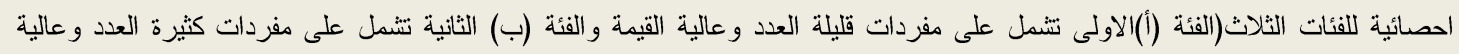

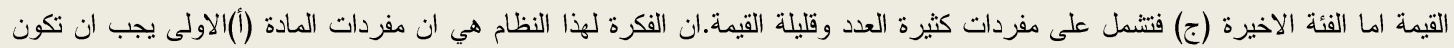

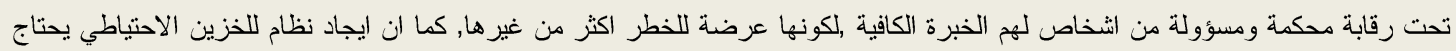

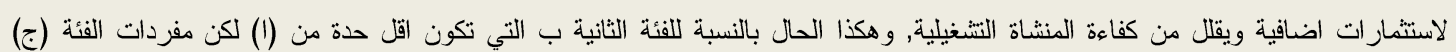
لاتحتاج الى اجر اءات رقابية بالحدة نفسها, فالحدود المعقولة لكل فئة عادة تكون كماياتي:- [8,p196

جدول (1) فئات المواد الخام الحاكمة

\begin{tabular}{|c|c|c|}
\hline 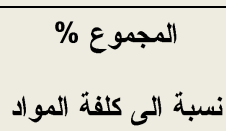 & ن المجموع المبة المفردات & الفئة \\
\hline$\Lambda \bullet-V$. & $1 .-0$ & i \\
\hline$r .-1$. & $r .-1$. & ب \\
\hline $1 .-0$ & $\Lambda \bullet-\vee$. & ج \\
\hline
\end{tabular}

r- مر اقبة المخزون

ويقصد بالمر اقبة متابعة مستمرة لإجر اءات العمل ومتطلباته بشكل واف ومتسلسل للوصول الى جودة الأداء المطلوبة, بتقويم نوعية الأداء وجو دته, و التي تتم بطريقتين:

أ -المر اقبة المستمرة: تتضمن ضو ابط يتم تصميمها ضمن المسار الطبيعي للأنشطة التشغيلية, ويتم تطبيقها بشكل فعلي وتلقائي, وتتمتع بالمرونة لتستجيب لأية تغيرات في الظروف المحيطة. علماً أن هذا النوع من المراقبة يتميز بسر عة اكتشاف نقاط الخلل لمعالجتها في الوقت المناسب. ب -التقويمات الاورية: فهي مجموعة من الأنشطة الرقابية نؤدى بشكل منفصل عن سير العمليات التشغيلية, ويتم لاحقاً بعد إتمام العمليات, وهنا

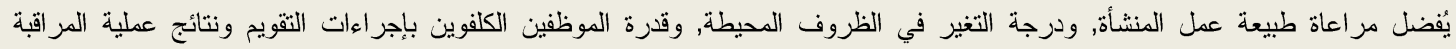

المستمرة للأنشطة وكفاءة إجراءات المر اقبة المستمرة. [12,389. 
وتعد عملية الرقابة على الذزين جزء اساسي من ادارة المواد, والذزين هو الاحتفاظ بشي؛ ملموس لمواجهة الطلب المستقبلي, تتجز عندها

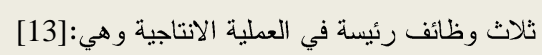

ا- انها بمثابة إطلاق العملية الإنتاجية بتوفير الرقابة وتخطيط الإنتاج مع تثرير الحالة المخزنية للمواد الخام والمنتجات النهائية. ץ- استمر ارية الرقابة الثخصية للمخزون بـــديث سجلات المواد الخام عن طريق مستتد، طلب المواد، طلب تجاوز المواد، بطاقات ارجاع المو اد. (يمثل ضابط رقابي لعدم ملاعمتها للإنتاج بالاستعمال الأفضل للموارد بتقليل التلف وزيادة الكفاءة التتشغيلية) r- وبعد استلام أمر العمل من آخر مركز عمل يقوم قسم الرقابة المخزنية بتسجيل الانتاج النهائي في سجلات مخزون المنتج النهائي.

ع - مفهوم الجودة وطبيعة تكاليفها:

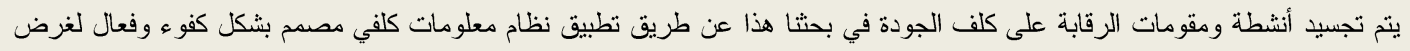

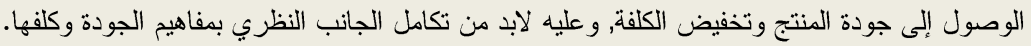

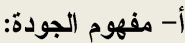

الجودة هي المطابقة للمو اصفات المحددة. [14,58] وان الجودة تمثل الناتج الكلي للمنتج أو الخدمة جراء دمج خصائص نشاطات التصنيع و الهندسة والتسويق والصيانة التي تمكن من تلبية حاجات ورغبات الزبون ينبغي على المنظمات الصناعية التي ترغب في البقاء بالمنافسة داخل

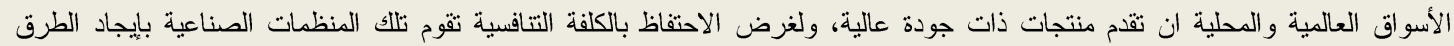

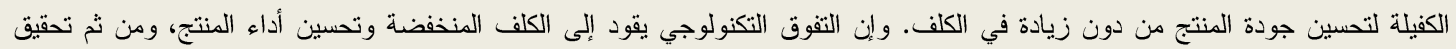
الجودة، ويعود استخدام التكنولوجيا الجديدة وتطوير مواد جديدة، بالإضافة إلى تحسين العمليات عن طريق الإدارة الأفضل والتدريب الجيد

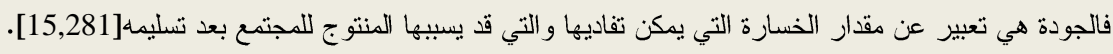
وكما عرفت بانها فلسفة قائمة على تطوير السيطرة الثاملة على الجودة عن طريق استعمال مجموعة الأدوات المتضمنة والمتعلقة برغبات الزبون والمنضمنة لخدمات مابعد الييع وبحوث السوق ودورة حياة المنتج وتطويره, ومتابعة العمليات وتجنب استعمال مواد أولية تالفة

وكذلك عرفت بأنها فلسفة تحتوي على ثلاثة مبادئ مهمة أو ضاغطة لتحقيق مستوى عالي من الجودة وأداء العمليات وتتضمن إرضاء

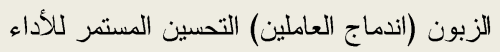
ب- معوقات الوصول بالمنتج الى الجودة المطلوبة ومنها: أ- نقص في التركيز على الزبون , فهناك مخاطر عدم رضا الزبون. ب-نقص في تعريف المنظمة للجودة , اهداف العاملين متقاطعة, نقص توجيه القضايا المختلفة, استخدام مقاييس مختلفة للنجاح ت-ضعف الاتصالات داخلية . ث-التركيز على النتائج المالية القصيرة الأمد. ج- عدم مرونة الخطة الاستر اتيجية وقابليتها للتغيير . ح-نقص في القيادة , يحتاج الى مدر اء قادة

ج- تعريف كلف الجودة:- عرفت على انها كلف تحدث لمنع منتجات غير مطابقة للمواصفات او منخفضة الجودة وتتعلق بازالة العيوب

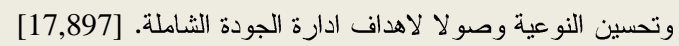
وأكد آخرون بأنها ذلك الجزء من الكلفة الذي يرافق نوفير منتج أو خدمة لا نتطابق مع المعايير الموضوعة، لكونها ترتبط بمنع الجودة الرديئة.

د- أنواع كلف الجودة يتم تبويب كلف الجودة إلى أربع مجاميع رئيسة وهي كلف الوقاية، وكلف التقييم، وكلف الفشل الداخلي، وكلف الفشل الخارجي. [19,252] الآتي تصنيف هده الكلف وتعريفاتها:

اولاًا كلف الوقاية(المنع)

هي الكلف التي تساعدعلى تجنب الجودة الرديئة للمنتجات او الخدمات مثل (هندسة الجودة - هندسة التصميم - تقييم المجزين - كلف التدريب - تقارير الجودة - تخطيط الجودة - صيانة المعدات),كلف تقييم للمجزين,كلف التصميم الهندسي,كلف تقييم عمليات المنتوج,كلف حماية [17, 898].(الموجودات 
و إنها تأخذ بمبدأ الوقاية من الأخطاء والعيوب , بالفحص والمراجعة , والتحليل المستمر لتحديد المعوقات قبل حدوثها , و إيجاد الحلول المناسبة

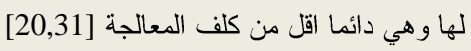

ثانياً- كلف التقييم(المنع)

هي الكلف الناجمة عن محاولة معرفة ما إذا كانت المنتجات مطابقة للمواصفات الموضوعة قبل تسويقه (فحص واختبار المواد الأولية -

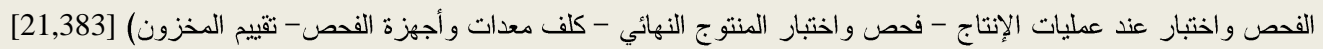

ثالثاً- كلف الفشل الداخلي

تعرف على أنها سلسلة متر ابطة من الإعمال أو النشاطات تهذف إلى تحقيق نتائج ذات قيمة أعلى بالتركيز على العملية بقصد تقليل التلف

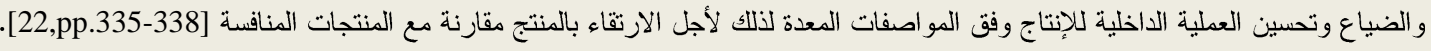

أو هي الكلف التي تحصل عند اكتناف العيوب في المنتجات قبل إرسالها للزبون منها كلف(- كلف التالف - كلف إعادة العمل - كلف فنثل

العملية - السماحات (تخفيض سعر الييع)- إعادة الفحص - كلف هندسة العملية والتصنيع المتعلق بالفشل الداخلي وإن المبدأ المهم من بين

المبادئ إدارة الجودة الشاملة هو التركيز على العملية التشغيلية ابتدا بالخام وانتهاء بالمنتج ومدى مطابقته للمعائية العيبر المعدة. [23,52]

رابعاً-- الفشل الخارجي

تتمثل بالكلف التي تحدث بسبب(عدم رضا الزبون,اعادة النظر في هذا الفثل,اعادة التصليحات على وفق ما ينبغي من الزبون , التعويضات

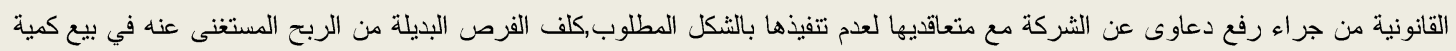

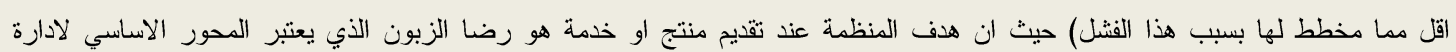

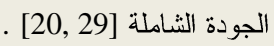

لذا يكون التركيز على كل من الزبائـن الخارجيين والداخليين ، إذ يحدد الزبائن الخارجيين جودة المنتجات والخدمات المستلمة، في حين

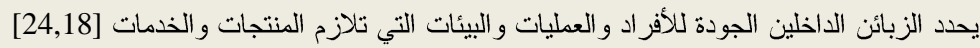

كما يكون للمنظمة مجزز خارجي ومجهز داخلي يمكن إن ينظر إلى الإدارات والأقسام داخل المنظمة على أنها مجزز داخلي وزبون

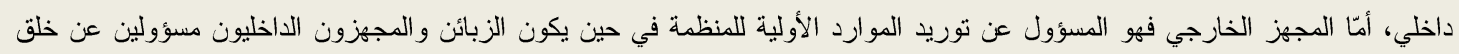

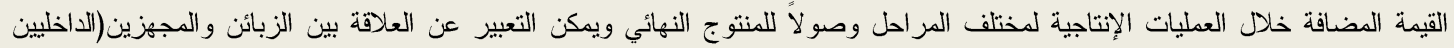

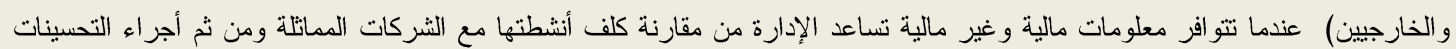

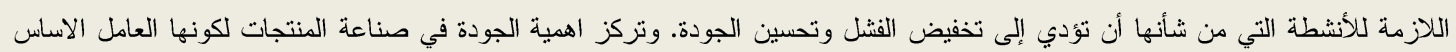

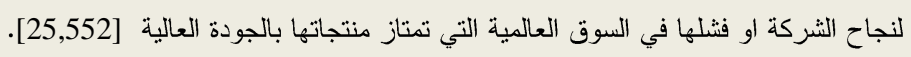

وأن المستوى الأمثل لكلف الجودة يحدث عندما يصل إلى مستوى المعيب الصفري (Zero Defect Level) كما أن الكلف الظاهرة و المخفية

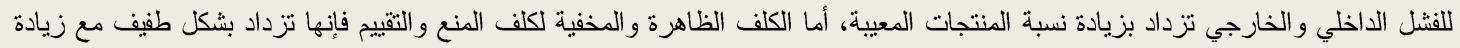
نسبة الوحدات المعيبة، وأن النقطة الأكثر أهمية هي إن الكلف الكلية للجودة نكون أدنى ما يمكن لمستوى المعيب الصفري. [26,68

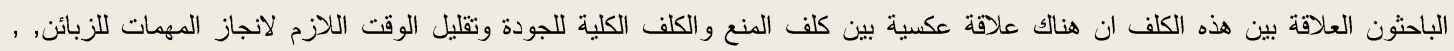

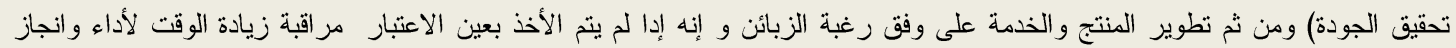

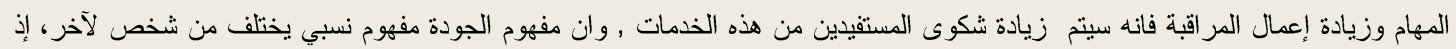

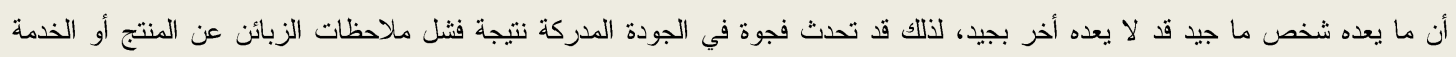

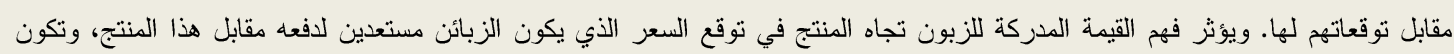

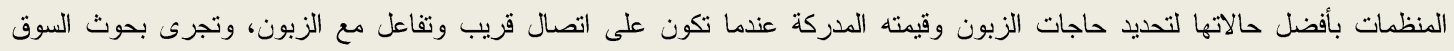

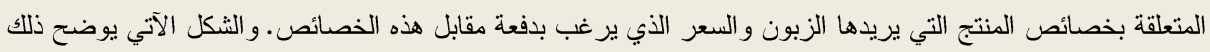




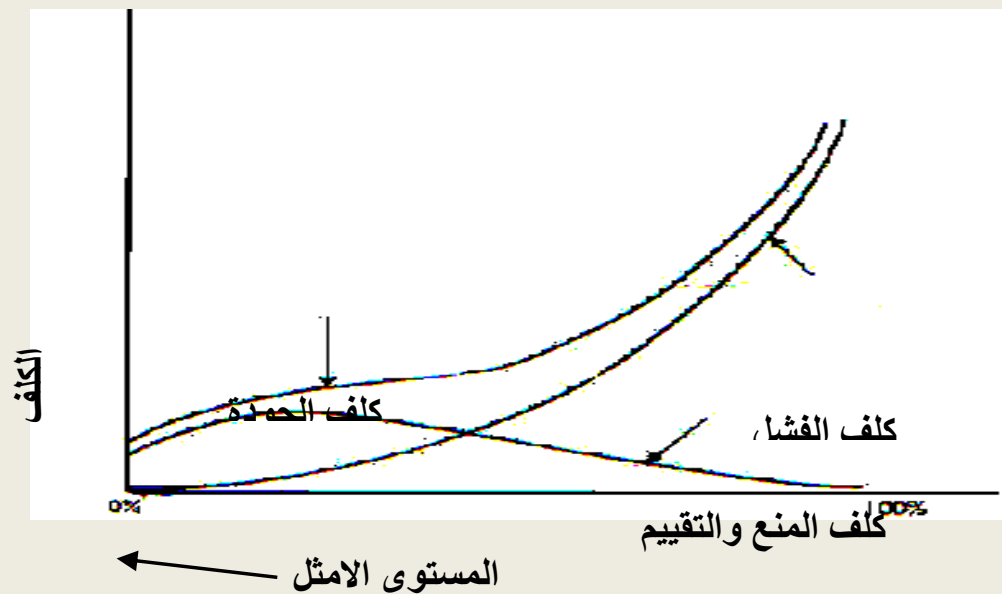

[26,p68] المصدر

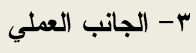

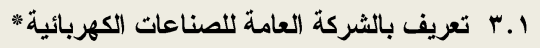

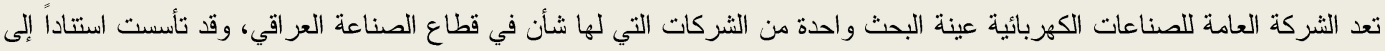

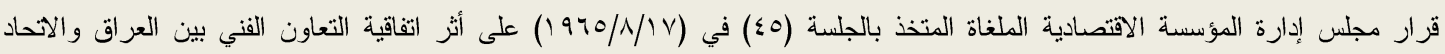

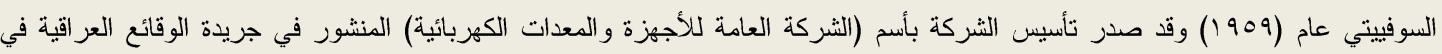

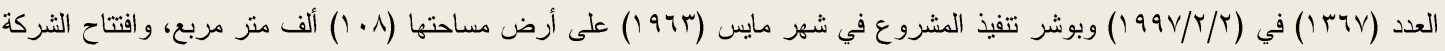

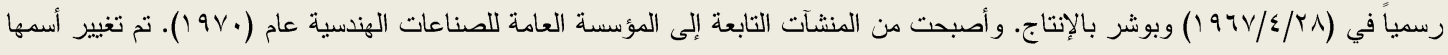

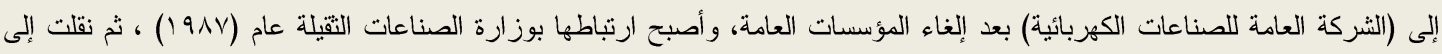

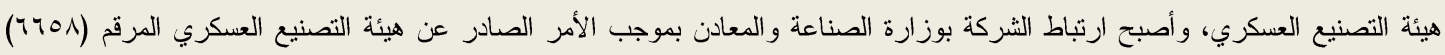

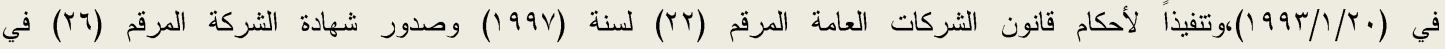

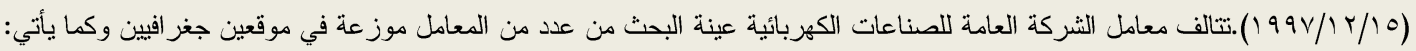

• معامل الوزيرية.

• معمل المصابيح الكهربائية/ التاجي وضمن المصانع الآتي:-

ا. مصنع المحركات: ويشتمل هذا المصنع على أربعة معامل (معمل محرك مبردة الهواء ومعمل المراوح ومعمل محرك المكيفة الثباكية

("اطن) ومعمل مضخة الماء المنزلية)

Y. مصنع المكيفات: يتكون هذا المصنع من ثلاث معامل رئيسة (معمل تموز لإنتاج المكيف الثباكي (1.5 طن)، (Y طن) , معمل الميلاد لإنتاج

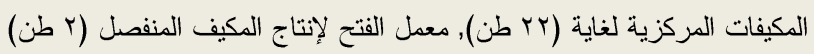

r. مصنع الأجهزة الكهربائية: يتكون من ثلاثة معامل تشكل مكونات مصنع الأجهزة الكهربائية، وهي(معمل قاعدة الفلورسنت, معمل قاطع

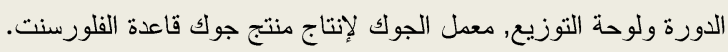

ع. المصنع الرئيس: يتخصص هذا المصنع بعمليات التثغيل الميكانيكي و إنتاج الأجزاء المختلفة لمنتجات الثركة بقوالب السباكة والقطع البارد و البلاستك، ويتكون هذا المصنع من المعامل (معمل الألمنيوم ومعمل الكابسات ومعمل الخراطة ومعمل البلاستك ومعمل تجميع مضخة الماء

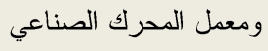

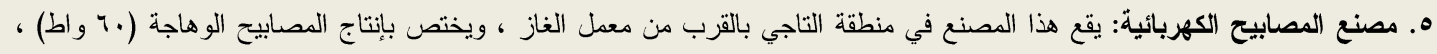

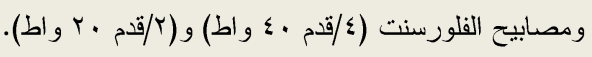

$$
\text { r.1. المصدر/ التقرير السنوي للشركة لعام * }
$$




\section{r.r مر احل تطور نظام معلومات محاسبة الكلفةعلى وفق واقع حال الثركة}

1- المرحلة الأولى - الار اسة التمهياية:

تكون هذه المرحلة ضرورية لإكتشاف المشاكل في النظام القائم او فرصة للتحسين والتطوير فيه ويتمثل عمل مصمم النظم هنا بتحديد

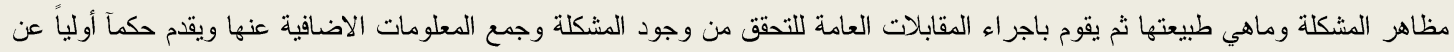

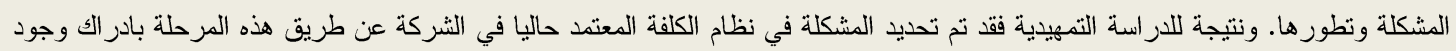

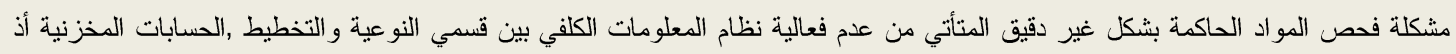

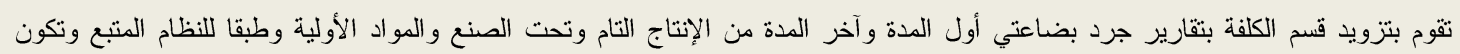

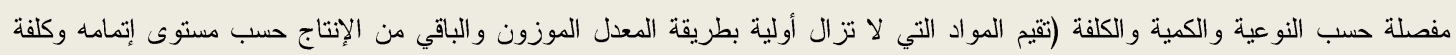

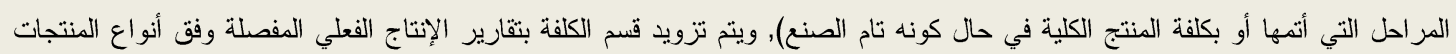

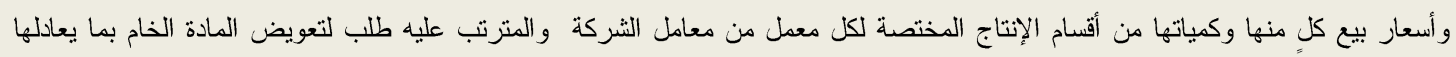

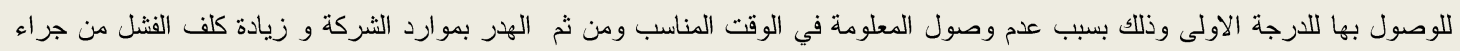

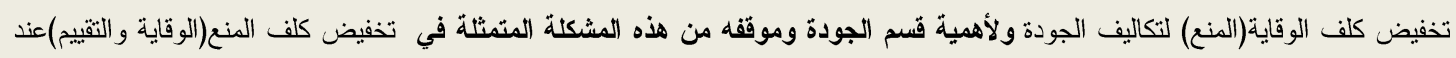

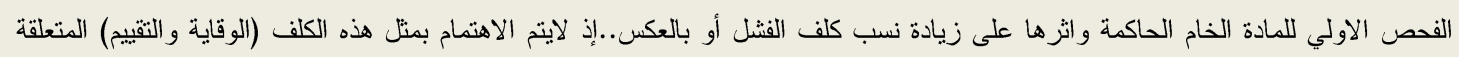

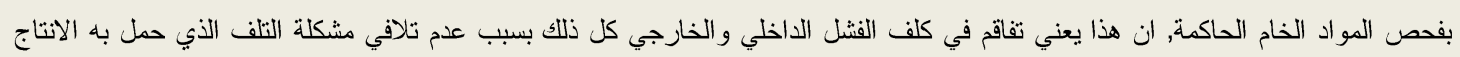

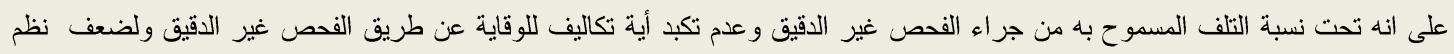

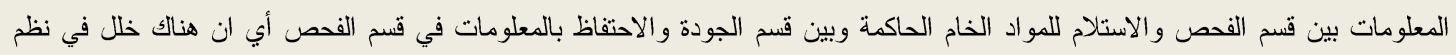

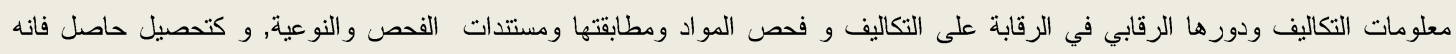

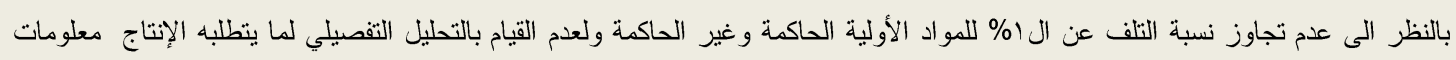

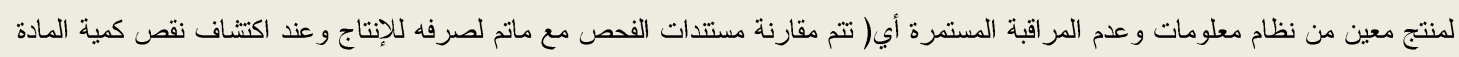

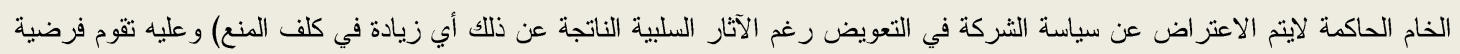

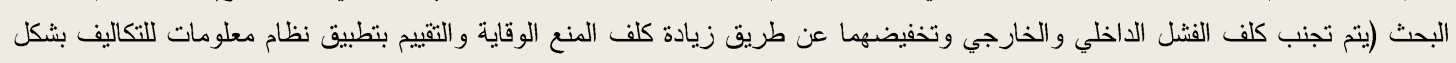

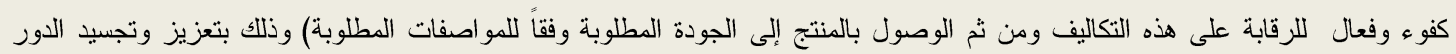

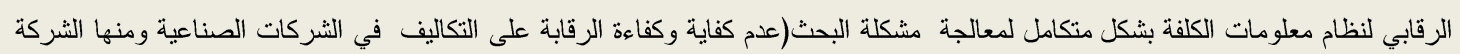

العامة للصناعات الكهربائية عينة البحث لاسيما الرقابة على كلف الجودة. الخ ضمن المنهجية اعلاه) ومن ثم تحقيق هدفه وتجسيد الهيته.

r- تطوير النظام القائم

للتعرف على ماهية تطوير نظام معلومات محاسبة التكاليف لابد من نتاول عناصره على وفق الآتي:

أ- مدخلات النظام:- اهم المدخلات وجود نظام معلومات كفوء وفعال لاهميته في توفير معلومات كلفوية لأجز اء ومكونات المنتج وتكلفة المواد

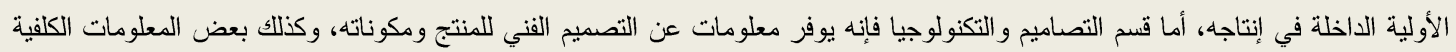

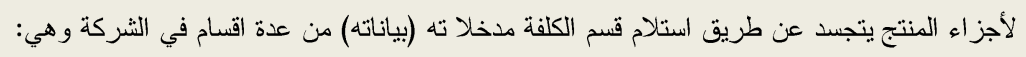

ا- التسويق: يزود قسم الكلفة بمعلومات عن كميات الأنتاج التام المستلم من قسم الأنتاج،كمية المبيعات, مردودات المبيعات(أسبابها لتحليل ان

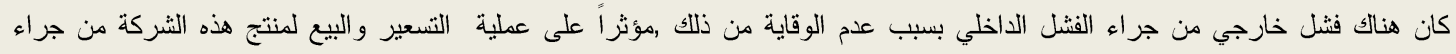

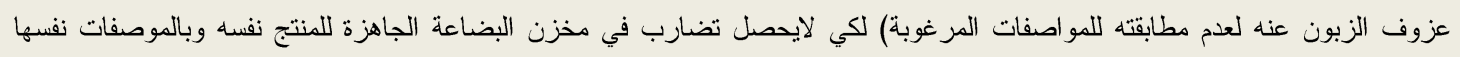

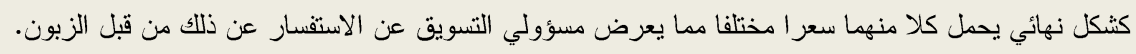
ץ- المخازن: تزود قسم الكلفة بكمية ونوعية المواد الأولية المصروفة للانتاج(تتاقل المعلومات بشكل سليم من والى وبين قسم الجودة والفحص

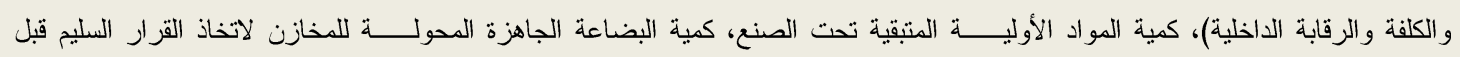

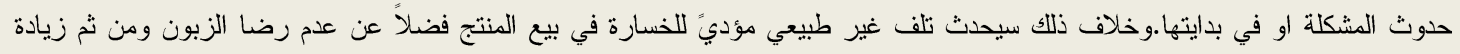

كلف الفتشل.

r- الإتتاج: يقوم قسم الانتاج بتزويد قسم الكلفة بمعلومات عن كمية الأنتاج الجيد ونو عيته كمية الوحدات التالفة على وفق المعلومات الأولية عن

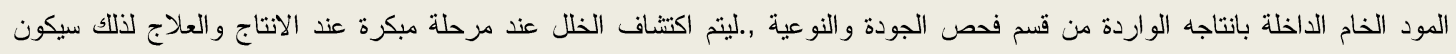

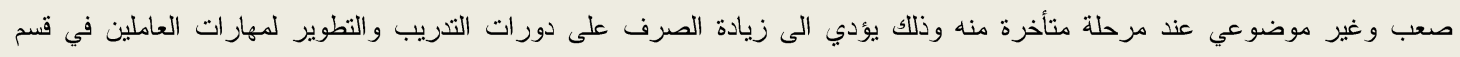

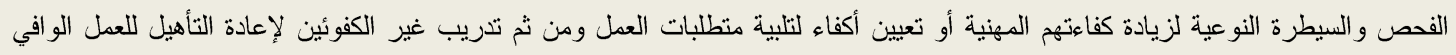

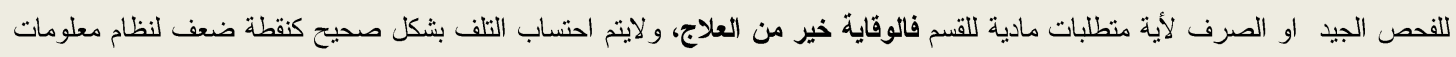

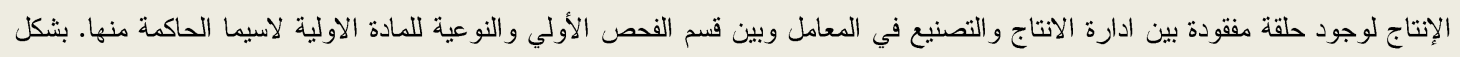



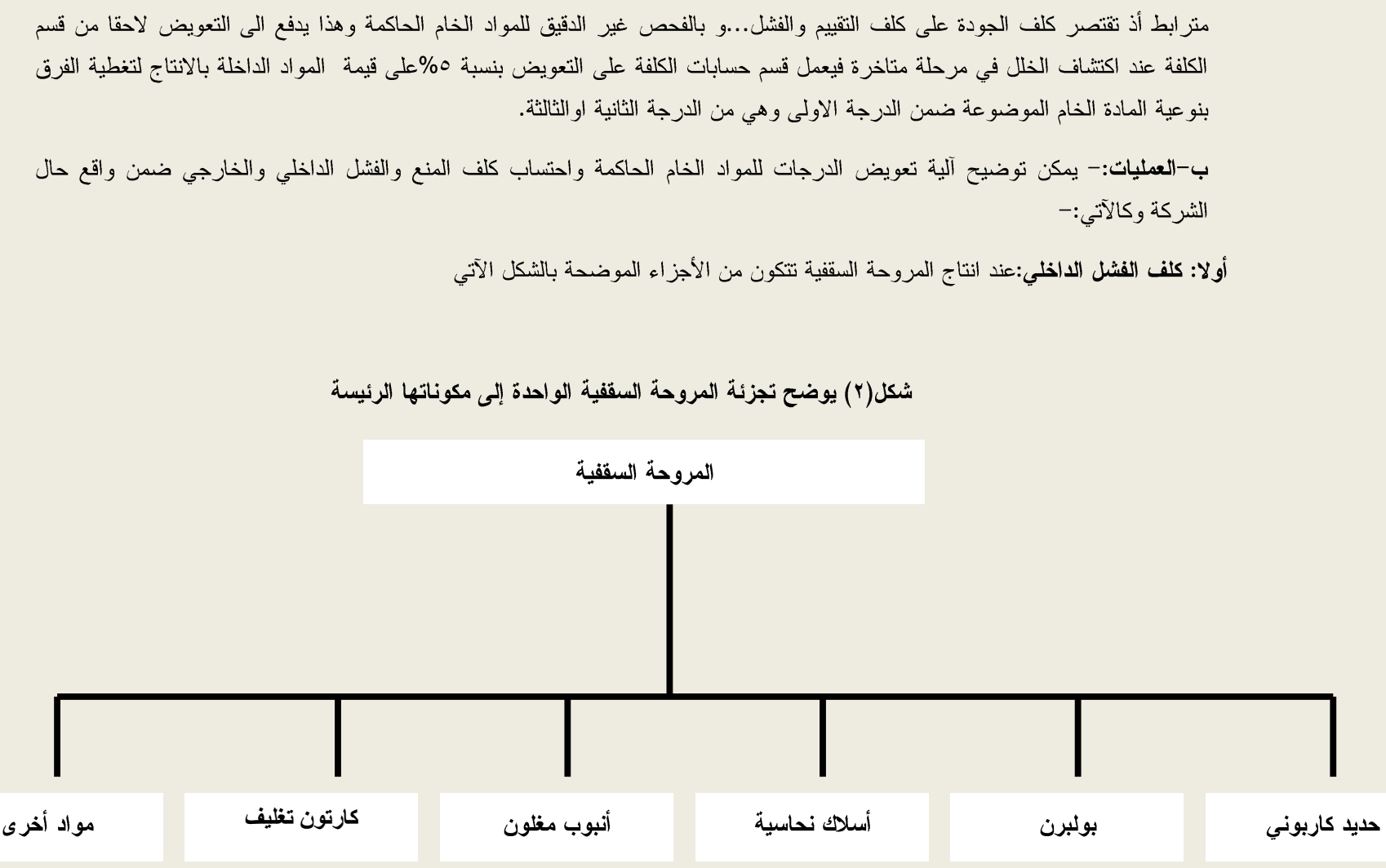

إعداد الباحثين بالاعتماد على المقابلات مع المهندسين في شعبة التكنولوجيا في الثركة 
جدول (ץ) يوضح كلفة المروحة السقفية الواحدة(صيغة قياسية)

\begin{tabular}{|c|c|c|c|c|}
\hline الكلقة & (الكمية)معدل الصرف & سعر الوحدة & وحدة قياس & المواد \\
\hline$|r 0| \wedge \mid$ & $0, r 94$ & r r بينار & كغم & حديد كاربوني \\
\hline 117 & r & $\varepsilon \cdot 1$ & قطعة & بول برنك \\
\hline rmq &., 109 & $1 \leqslant q 41$ & كفم & و واير \\
\hline 170. & 1 & 170. & قطعة & كارتون تظليف \\
\hline 09 . &., .09 & $1 \ldots$ & روطة & أنبوب مغلون \\
\hline 119.0 & & مختلفة & مختلفة & مواد أخرى \\
\hline rधाII & & & & إجمالي تكاليف المواد \\
\hline raor & & & & تكاليف تشغيلية \\
\hline TVOTE & & & & مجموع التكاليف \\
\hline 194. & & & & تكاليف إدارية وتسويقية \\
\hline Irv\&.r & & & & الكلفة الكلية \\
\hline
\end{tabular}

إعداد الباحثين بالاعتماد على بيانات قسم الكلفة لعام ( • + ץ) في الثركة

في هذا الخط الإنتاجي,تصرف المواد الأولية للإنتاج بدايةً من مركز الكلفة الاول وصولاً للمركز الاخير واجراء بقية العمليات النهاية ريفاجئ مسؤول الإنتاج بان المواد المصروفة هي من الدرجة الثانية (عند مراحل تصنيعه) وعليه يتم تعويض هذه الكمية من الدرجة الثانية كسياسة متبعة في الشركة للوصول الى الدرجة الاولى(على وفق المعادلة الفنية) سيكون بنسبة ه\% كالآتي:- ( بالصيغة القياسية المذكورة

جدول رقم(ץ) استخراج الكمية التعويضية والمضخمة للمواد الأولية الداخلة

\begin{tabular}{|c|c|c|c|c|c|}
\hline الكمية المضخمة & $\begin{array}{c}\text { الكمية التعويضية } \\
(r \times 1)\end{array}$ & 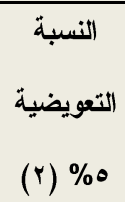 & الكمية المخططة & اسم المادة & $ت$ \\
\hline דצו, 0 كغم & 194ץ , • كغم & $\%$ & ד ז, • كغم & حليد كاربوني & 1 \\
\hline قطعة Y, قطعة & ..... & $\%$ & r بطعة & بول برنك & $r$ \\
\hline & • • . . . . .كغم & $\%$ & 109 1, • كفم & واير & $r$ \\
\hline •^^^•, • روطة & . . ه१ץ, .روطة & $\%$ & ه ه., · روطة & انبوب مغلون & $\varepsilon$ \\
\hline
\end{tabular}


جدول رقم (๕) استخر اج كلفة التتف للكمية التعويضية

\begin{tabular}{|c|c|c|c|c|}
\hline كلقة التتف & سعر الشراء & الكمية التعويضية & اسم المادة & ت \\
\hline צ৭ץ r . ع ا دينار & r Or & 194 ז, • كغم & حديد كاربوني & 1 \\
\hline ^, • ؛ دينار & ^ •ـ ـ د/ قطعة & . . . . . . قطعة & بول برنك & $r$ \\
\hline ๑, ૧ १ ه دينار & | & 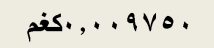 & واير & $r$ \\
\hline ג ו Y IVo دينار & .... . . د/روطة & ... •وץ, .روطة & انبوب مغلون & $\varepsilon$ \\
\hline
\end{tabular}

المصدر - اعداد الباحثون

وبهذه الآلية المتبعة من قبل الثركة تعتقد الثركة انها ستحافظ على القيمة الاجمالية للمواد الاولية في استمارة الكلفة فان لم تتم التغطية

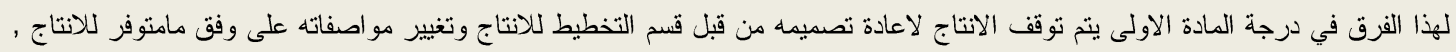

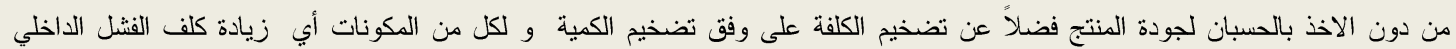

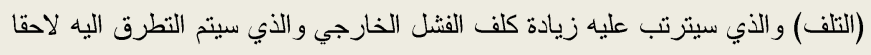

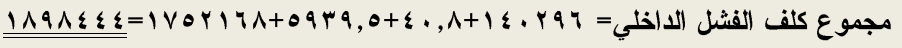

هنا تكمن المثكلة فيما لوتم وجود نظام معلومات كلفة فعال وكفوء معزز ومدعوم بنظام رقابي كفوء, في الثركة بالسياق الصحيح

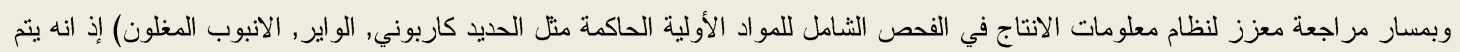

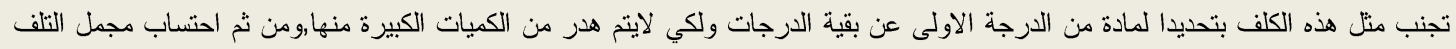

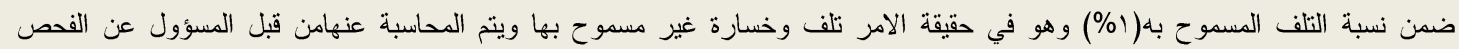
النوعي للمادة الاولية

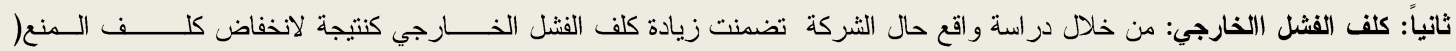

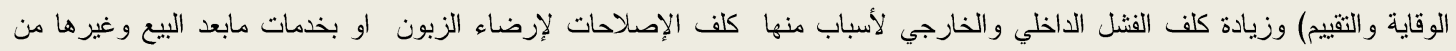

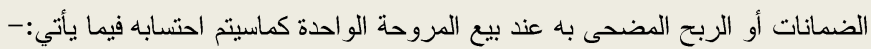

أ-كلف الاصلاحات و التعويضات:فيما يلي جدول رقم (0) يوضح كيفية استخر اج الكلفة المضخمة للمو اد الاولية

جدول رقم (•) لاستخراج الكلفة المضخمة للمواد الأولية

\begin{tabular}{|c|c|c|c|c|c|}
\hline $\begin{array}{c}\text { الكلف المضخمة }{ }^{r}(Y \times 1 \\
\end{array}$ & 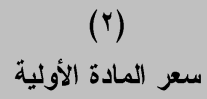 & الكمية المضخمة (1) & وحدة القياس & المكونات & ت \\
\hline rq\& & r هدينار & 0,747 & كفم & كاربوني & 1 \\
\hline$\wedge \vee_{0}$ & $\varepsilon \cdot \Lambda$ & $r, 1$ & قطعة & بولبرن & r \\
\hline$r . \Delta V, I r r$ & $1 \leqslant 941$ & $\cdot, r, \leqslant V \theta$ & كفم & واير & $r$ \\
\hline$\wedge \wedge 0$ & $1 \ldots$ & $\cdot, \cdot \wedge \wedge \theta$ & روطة & مغلون & • \\
\hline
\end{tabular}

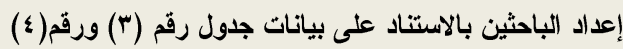


وبعد استخر اج الكلفة المضخمة للمو اد الاولية يتم في جدول رقم(0) استخر اج الفرق بين الكلف المضخمة والفعلية للمواد الاولية.

جدول رقم(؟)الفرق بين التكلفة الفعلية، والكلفة المضخمة للمروحة السقفية

\begin{tabular}{|c|c|c|c|c|}
\hline $\begin{array}{c}\text { الزيادة في كلف الفشل (الخل } \\
\text { الخارجي } \\
\text { (دينار) }\end{array}$ & 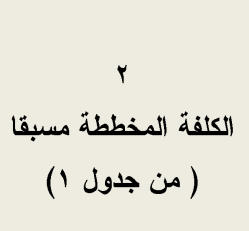 & 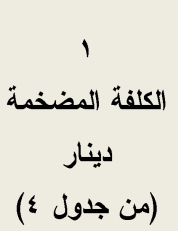 & المكونات & ت \\
\hline $109 \leqslant 01$ & $|r 0| \wedge \mid$ & rasTrY & حديد كاربوني & 1 \\
\hline 09 & 117 & Avo & بولبرن & r \\
\hline$\checkmark 11$ & rryq & $r . \Delta V$ & واير & $r$ \\
\hline ras & 09 . & 110 & انبوب مغلون & $\varepsilon$ \\
\hline 17.594 & $\mid r \wedge \varepsilon \cdot r$ & Yq৭ $q \leqslant q$ & \multicolumn{2}{|c|}{ المجموع } \\
\hline
\end{tabular}

إعداد الباحثين باستعمال بيانات الثركة في احتساب كلف الفشل الاخلي السابق

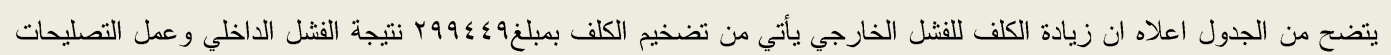

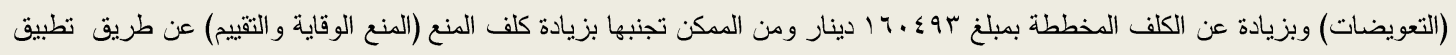

نظام معلومات محاسبي كفو \&.

ب- الربح المضحى به( كلفة الفرصة الضائعة) تتمنل هذه الكلفة بربح مضحى به بسبب حدوث

خسارة كبيرة لكافة المنتجات المتعاقد عليها و بشكل غير مدروس علميا وعمليا يتم اضافة هامش الربح بشكل اكثر من المعتاد على كميات

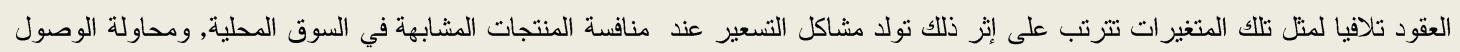

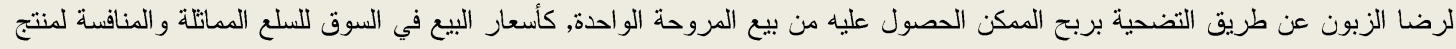

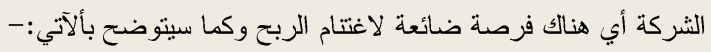
على وفق سعر بيع الشركة للمرحة السقفية (... (Y. دينار/مروحة, سيتم تخفيضه بنسبة التعويض التي اتبعتها الشركة(0\%) وكنتيجة للتضخيم بالكلف من جراء التلف غير الطبيعي سيقل الربح أي:-

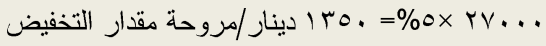

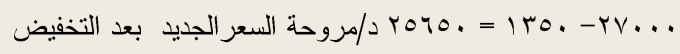

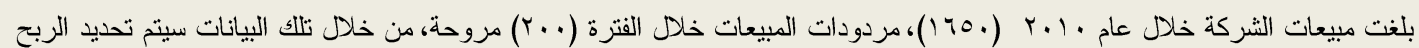

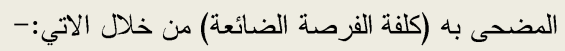

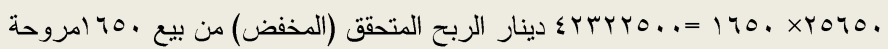

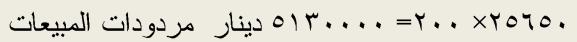

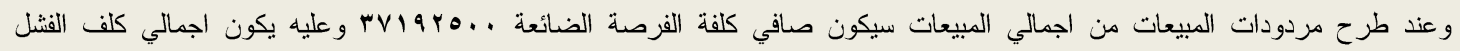
الخارجي (صافي كلفة الفرصة البديلة + كلفة الإصلاحات)

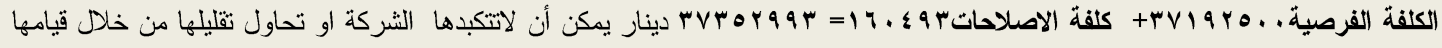
بزيادة كلف المنع وتجنب كلف الفشل الخارجي كما تم احتسابها اعلاه. 
ثالثاً: كلف المنع (الوقاية و التقييم)

أ-أنشطة المنع: من خلال دراسة واقع حال الثركة و من دراسة مشكلة البحث يتضح ان كلف المنع او التجنب قليلة إن لم تكن معدومة و عليه يتم احتساب كلف المنع وفق الاتي:

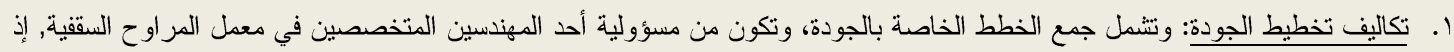
يقوم بإصدار شهادة فحص بعد كل نقطة من نقاط الفحص فضلاً عن قيامه بتطوير وتتفيذ برامج ونظم إدارة الجودة من أجل المحافظة على ونى

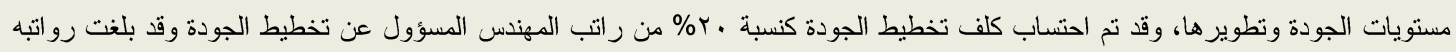

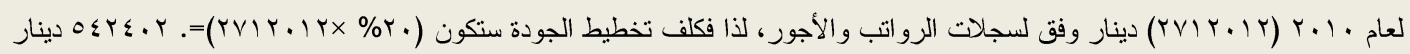
r. تكاليف تصميم الجودة: وتكون من مسؤولية نشاط البحث والتطوير، إذ يقوم بتطوير منتجات الثركة الحالية أو حل المشكلات المتعلقة بجودة

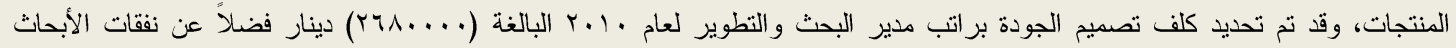

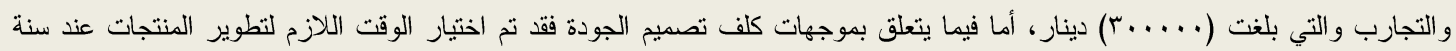

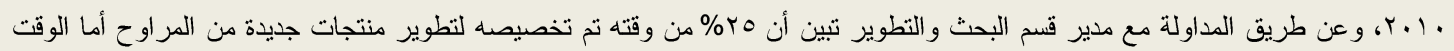

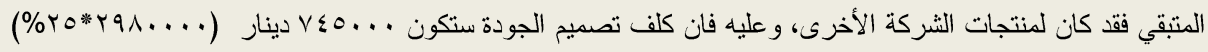

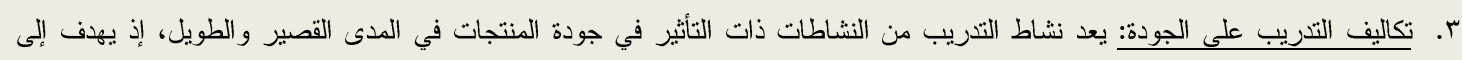

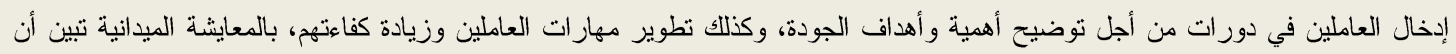

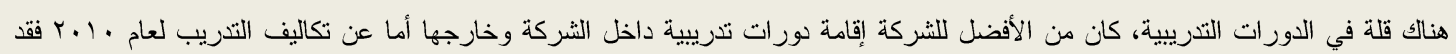

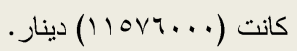

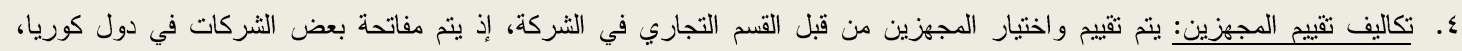

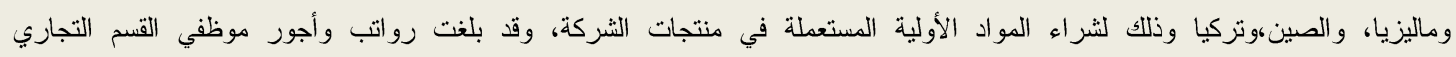

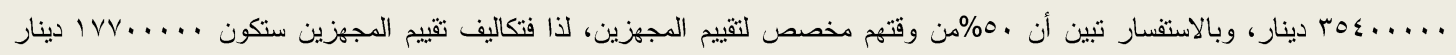

. $(\% 0$. x ros ....)

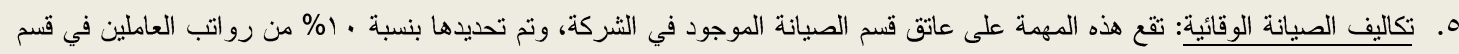

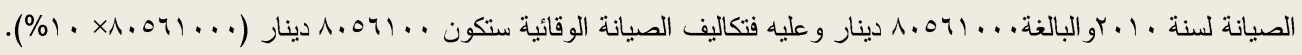

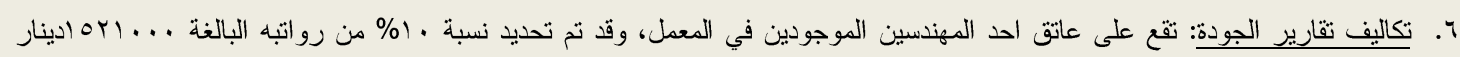

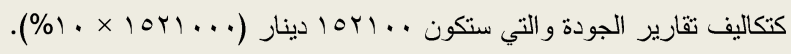

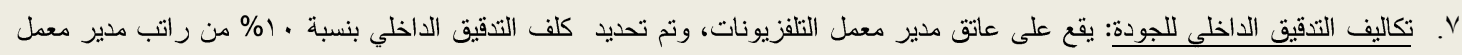

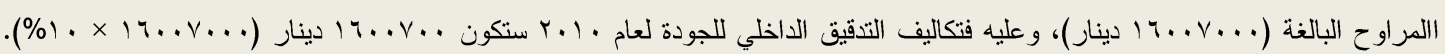
وإيجاز ألما تقدم فان تكاليف أنشطة المنع يمكن توضيحها بالجدول الآتي.

جدول رقم(7) تكاليف نشاطات المنع لعام 2010 بالاينار

\begin{tabular}{|c|c|c|}
\hline المبلغ & التفاصيل & $ت$ \\
\hline $0 \leqslant r \varepsilon \cdot r$ & تكاليف تخطيط الجودة & 1 \\
\hline$v \leqslant 0 \ldots$ & تكاليف تصميم الجودة & 2 \\
\hline $11087 \ldots$ & تكاليف التدريب على الجودة & 3 \\
\hline $\operatorname{lv} \vee \ldots$ & تكاليف تقييم المجهزين & 4 \\
\hline$\Lambda .07 \ldots$ & تكاليف الصيانة الوقائية & 5 \\
\hline lori... & تكاليف تقارير الجودة & 6 \\
\hline $17 \ldots .$. & تكاليف التدقيق الداخلي للجودة & 7 \\
\hline$\varepsilon V \cdot V V Y \cdot r$ & & \\
\hline
\end{tabular}


ج- المخرجات:- بعد إجر اء هذه العمليات وحفظ أولياتها في ملفات خاصة ترسل هذه المستتدات المحفوظة بملفاتها إلى قسم الكلفة وخلاف

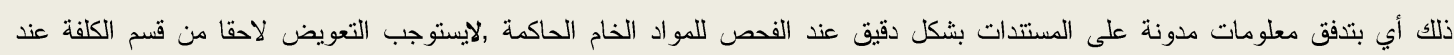

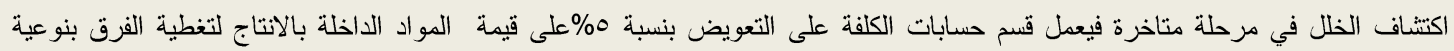

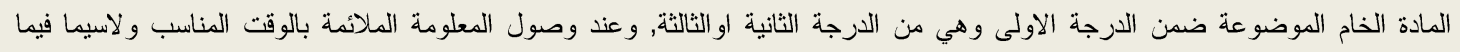

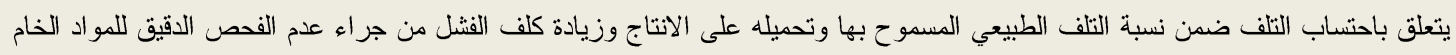

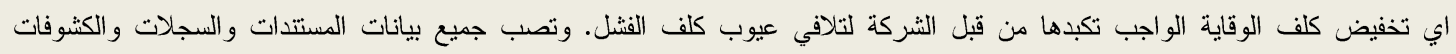
و التقارير بشكل أو بآخر سواءٌ أكانت بصورة مباشرة أو غير مباشرة في مدخلات نظامنا تحت الدراسة لمعالجتها واستخدامها في ايجاد

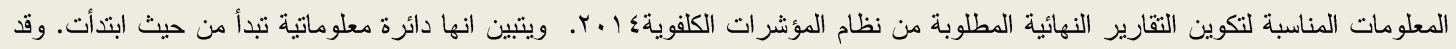

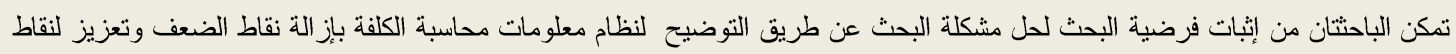

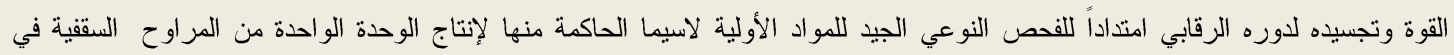

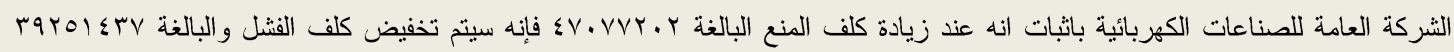

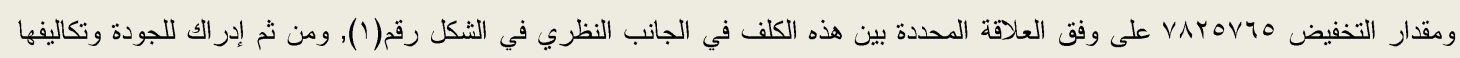
من ثم الاستفادة من تطبيقها في الشركات الأخرى ككل.

ع - الاستنتاجات و التوصيات

1 - 1 - 1 الاستنتاجات

1- بعف في كفاءة نظام معلومات الكلفة. r- اخفاق وصعوبة تدفق المعلومة المناسبة في الوقت المناسب بين المستويات الادارية ذات العلاقة r- صعوبة الرقابة على الكلف لاسيما كلف الجودة. ع- هدر اللموارد المتاحة في الشركات الصناعية.

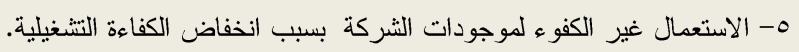

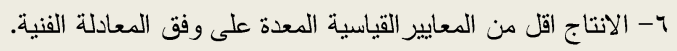

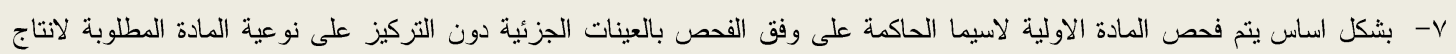

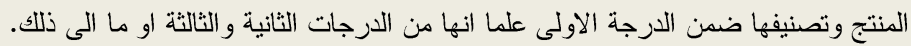

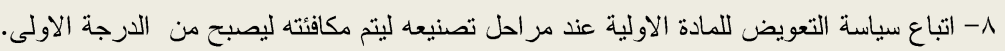
9- احتساب التلف بشكل غير دقيق (اي تحت نسبة/\%) و المتضمنة للتلف غير الطبيعي ايضا وتحميله على الاتتاج مباشرة.

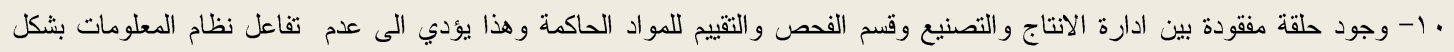
كفوء ومن ثم يؤثر سلبا على جودة المنتج.

r. ب التوصيات النظرية والعملية ا- التوصبيات النظرية: 1- زيادة كفاءة نظام معلومات محاسبة الكلفة في الثركة وتحسينه بشكل مستمر. r- ينطلب تدفق المعلومة المناسبة ووصولها في الوقت المناسب للمستفيدين منها بين المستويات الادارية ذات العلاقة باحتساب كلفة المنتج.

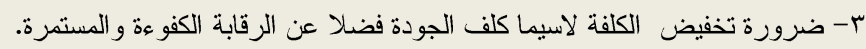

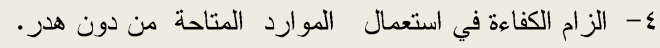
ه- الحفاظ على موجودات الشركة ومن ثم زيادة الكفاءة التشغيلية.

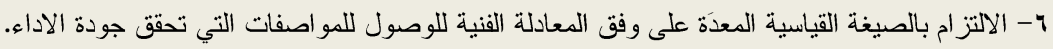

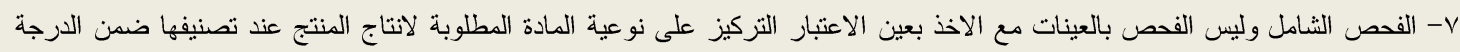
الاولى و عند فحص المادة الاولية لاسيما الحاكمة.

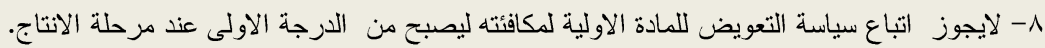
9- لايمكن احتساب التلف غير الطييعي ضمن التلف الطبيعي المسموح وتحميله على الانتاج وانما يتم احتساب التلف بشكل دقيق (ابي نسبة (لإ) و المتضمنة للتلف الطبيعي فقط. 


\section{CONFLICT OF INTERESTS}

There are no conflicts of interest.

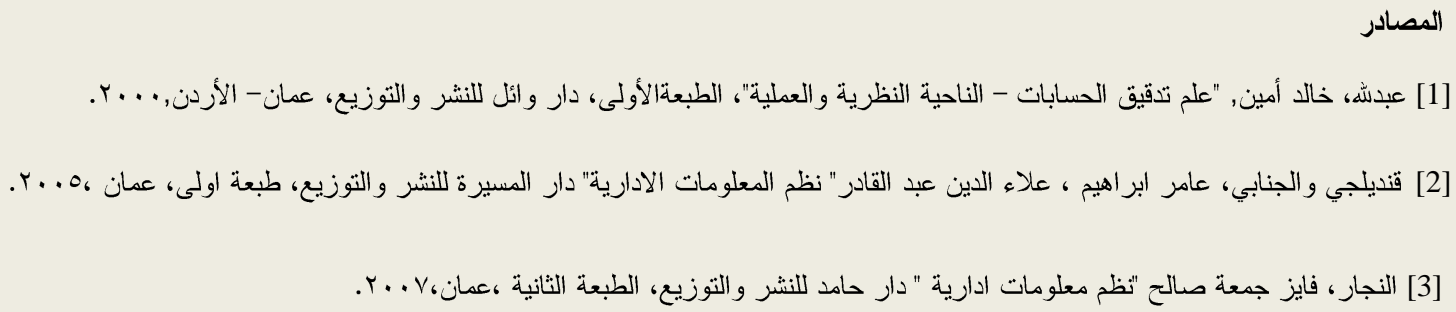

[4] Drury, Colin : "Management And Cost Accounting", $7^{\text {th }}$ ed., Thomas learning, Printed by Canale C, Italy. 2008.

$$
\text { [5] النظام المحاسبي الموحد, ديوان الرقابة المالية في العر اق, الطبعة الثانية , , II. }
$$

[6] Atkinson. Anthony A., Kaplan, Robert S. \&Matsumura, Ella Mae. \&Young, S. Mark, "Management Accounting", $5^{\text {th }}$ ed., Prentice Hall, Inc, 2007.

[7] Roby Sawyers \&Steve Jackson: "Managerial AccountingAfocus on Decsion Making", $2^{\text {nd }}$ ed.,2001,Thomson,South Westren.

$$
\text { [8] خضير كاظم حمود, هايل يعقوب فاخوري, ادارة الانتاج و العمليات دار صفاء للنشر والتوزيع- عمان، الطبعة لإولى, 9 .... }
$$

[9] www.ibtesma.com/vb/shotread-139530.html

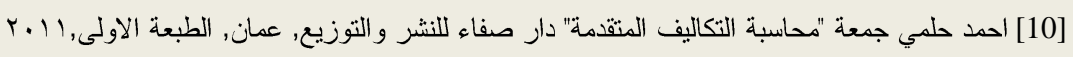

[11] سعد، سلمى منصور ونجم ، بصيرة مجيد،" دور المعلومات المحاسبية في تحقيق الميزة التتافسية باستخدام ادارة الجودة الثاملة"، بحث

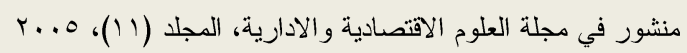

[12] محمد عبدالقادر الديسطي و أحمد حامد حجاج تزجمة ل أرينز، ألفين و لوبك جمس "المراجعة مدخل متكامل"، دار المريخ للنشر،

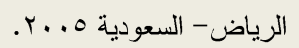

\section{[13] www.tknt/vb/t26137.htm}

[14] Besterfield, Dale "Quality Control" $8^{\text {th }}$ ed., Pearson Education, Inc., 2009

[15] Kulkarni, Vinay \& Bewoor, Anand "Quality Contro" $1^{\text {st }}$ ed, Wiley India, Pvt. Ltd, 2009

[16] Kumar, S. Anil \& Suresh, N. "Production and Operations Management" $1^{\text {st }}$ ed., New age International (P) Ltd., 2006.

[17] Horngren T. Charles, Walter T.Harrison jr \&Olivr M.Suzanne "Financial \& Accounting" $13^{\text {th }}$ ed, Person, Indiaan Polis New Yourk San Francisco, 2012.

[18]Goodman,Stephen \& Fandt, Patricia \& Michlitsch, Joseph \& Lewis, Pamela. "Management Challenges For Tomorrow's Leaders" $1^{\text {st }}$ ed., Thomson, South - Western , 2007.

[19]عبيد، انتصار احمد، وحليحل، جليلة عيدان، "ـاثز تحليل كلفة النوعية على اساس الانشطة في تحقيق الميزة النتافسية"، مجلة العلوم

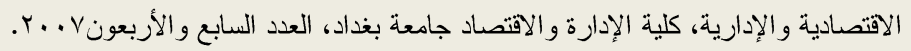

[20] التميمي، ماجدة عبد اللطيف، "مدى تأثير تطبيق معيار Six Sigma باستخدام البرامج المحوسبة على منحى كلف الفشل الداخلي

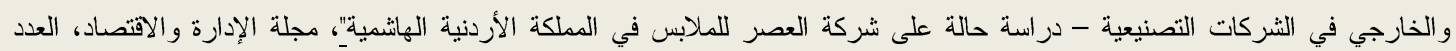
الثالث و السبعون، 2008. 
[21] Morse, Wayne J., \& Davis, James R. \& Hartgraves, ALL.,"Management Accounting: A Strategic Approach", $3^{\text {rd }}$ ed., Printed in the United States of America, 2003.

[22] الفضل، مؤيد عبد الحسين، والطائي، يوسف حجيم،"إدارة الجودة من المستهلك إلى المستهلك...منهج كمي"، مؤسسة الوراق للنشر

والتوزيع، عمان، الأردن، 2004.

[23] Summers, Donna C.S. "Quality" $4^{\text {th }}$ ed., Pearson Education, Inc., 2006.

[24] Goetsch, David \& Davis, Stanley "Quality Management" $5^{\text {th }}$ ed, Pearson Education, Inc., 2006.

[25] Hilton, Ronald W. \& David E.Platt "Managerial Accounting, creating value in a global business environment," $9^{\text {th }}$ ed. , McGraw - Hill Com. , North America, 2011.

[26] Garrison, Ray, H. \& Noreen, Eric, W.,"Managerial Accounting", 11 $11^{\text {th }}$ ed., McGraw-Hill, Singapore, 2008. 